\title{
Use of participatory scenario modelling as platforms in stakeholder dialogues ${ }^{\#}$
}

\author{
Lotta Andersson ${ }^{1 *}$, Johanna Alkan Olsson ${ }^{2}$, Berit Arheimer ${ }^{1}$ and Anna Jonsson ${ }^{3}$ \\ ${ }^{1}$ Swedish Meteorological and Hydrological Institute, SE-601 76 Norrköping, Sweden \\ ${ }^{2}$ Lund University, Sweden \\ ${ }^{3}$ Linköping University, Sweden
}

\begin{abstract}
A participatory methodology, based on dialogues between stakeholders and experts has been developed and tested in the drainage area to Kaggebo Bay in the Baltic Sea. This study is focused on the EU Water Framework Directive, with emphasis on reduction of eutrophication. The drainage area is included in the WFD administrative area of the Motala Ström River basin. A similar approach is now applied in a recently initiated project in the Thukela River basin, with focus on impacts of climate change on water resources. The methodology is based on the idea that a catchment model serves as a platform for the establishment of a common view of present conditions and the causes behind these conditions. In the following steps, this is followed by model-assisted agreement on environmental goals (i.e. what do we want the future to look like?) and local agreement on a remedy or mitigation plans in order to reduce environmental impact (e.g. eutrophication); alternatively to adapt to conditions that cannot be determined by local actions (e.g. climate change). By involving stakeholder groups in this model-supported stepwise process, it is ensured that all stakeholder groups involved have a high degree of confidence in the presented model results, and thereby enable various actors involved to share a common view, regarding both present conditions, goals and the way to reach these goals. Although this is a process that is time- (and cost-) consuming, it is hypothesised that the use of this methodology is two-pronged: it increases the willingness to carry out remedies or necessary adaptations to a changing environment, and it increases the level of understanding between the various groups and therefore ameliorates the potential for future conflicts. Compared to traditional use of model results in environmental decision-making, the experts' role is transformed from a one-way communication of final results to assistance in the various steps of the participatory process.
\end{abstract}

Keywords: participatory, catchment, coastal zone, modelling, nutrients

\section{Introduction}

Successful integrated water resources management (IWRM) need to be based on adaptive management approaches that can cope with uncertainties caused by globally as well as locally changing socio-economical and climate conditions (Pahl-Wostl, 2007). In addition, involvement of stakeholders is today seen as crucial for the mitigation of environmental problems. Public participation may contribute to achieving several interrelated goals such as better-informed stakeholder groups, transfer of knowledge and information from local stakeholder groups to regional and national planning and research, socially accepted mitigation measures, leading to higher efficiency in implementation and reduction of conflicts between stakeholder groups (Lauber and Knuth, 2000; Pahl-Wostl, 2002).

To be able to deal with the complex interaction of socioeconomic and natural processes, Information Communication Technology (ICT) facilitated participatory projects have been carried for a multitude of water resource management issues around the

\# $\quad$ Revised paper. Originally presented at the symposium 'HELP in Action: Local Solutions to Global Water Problems - Lessons from the South' which was held at the Emperor's Palace, Johannesburg, South Africa from 4 to 9 November 2007.

* To whom all correspondence should be addressed.

+4611 49581 44; fax: +46 1149580 01;

e-mail: lotta.andersson@smhi.se globe (e.g. Eakin et al., 2007; Gaddis et al., 2007). Participatory modelling has been suggested as a platform that could be a meeting point for synthesising information and involving various actors in decision processes (e.g. Alkan Olsson and Andersson, 2007, Duvail and Hamerlynck, 2003). However, especially in developing countries, but also in developed, the access and usefulness of available ICT is often an obstacle to use in participatory processes (Horlitz, 2007). Another crucial issue concerns how interest groupings interact across and between scales and how imbalances in negotiation power are reflected in participatory decisions (Sherwill et al., 2007). Computer-based models by definition include uncertainties since they are based on generalisations of both processes and physiographical conditions, as well as on available datasets. However, models provide a way to synthesise present knowledge and complex relations to give solid background information that is able to synthesising the understanding of the present situation, as well as produce predictions of future conditions (scenarios). Such scenarios can include assessments of human impact on natural systems, as well as of the effect of different remedies aiming to limit unwanted environmental impacts, or of the potential of various adaptation strategies.

Although models present a simplification of complex systems, they can thus be considered useful in environmental planning. Outputs from scenario-impact analyses put environmental changes in a tangible spatial and temporal perspective. Moreover model-derived information can be used to minimise the risk that discussions are blocked by biased perceptions of the causes to 
prevailing environmental conditions and of the potential impact of remedies. It can also make it possible for actors to see where their views and interest conflict, and how they can be bridged. A strict 'science based' approach that stresses optimal utilisation of water resources from a natural scientific and/or economical perspective may, not be perceived as beneficial by all stakeholders or policy makers, neither at the local or the regional level. As argued by Schulze (2001) the use of models as a policymaking tool makes it necessary for scientists to adapt from a 'research thinking' to a more outcome based 'policy thinking' to fit the needs and demands of stakeholder groups involved in a policy process. To guarantee that scenarios will be seen as a legitimate tool in the planning process, stakeholders at different levels must be involved in the validation of the input and outputs from the models.

Traditionally, scenario production has been used as a oneway communication of results from scientists to stakeholders. Often model applications have been based on general datasets, sometimes nation-wide, with less accuracy for local conditions. Due to the high cost for local data collection, this is usually the only manageable way to work on a national scale. However for regional and local applications, the feasibility of using a model is highly dependent on the access to representative time series and geographical data at these levels. When models are applied on a local level result will only contribute to integrated water resource management if used databases and assumptions are ratified by local authorities and other stakeholders as they often are familiar with the conditions of their catchment.

However, participation from different stakeholder groups in a process is not a guarantee that the project and resulting outcome will be transparent, representative, locally validated and democratic. Jonsson and Alkan-Olsson (2005) grouped factors that influence the degree of success of stakeholder involvement in a participatory environmental modelling process into three categories: factors influencing the willingness of stakeholders to invest time and resource in participation in the process, factors influencing the tendency of stakeholders to accept 'expert' results as legitimate descriptions of local ecosystems, and factors defining the 'room of action' for stakeholders to implement remedies suggested by model results.

By involving stakeholder groups in various parts of the modelling process, the 'participatory modelling' concept presented in this paper is aiming at serving as a platform for facilitating stakeholder participation in environmental planning at the local/ regional level. We hypothesise that, in contrast to a traditional one-way communication of model results in environmental planning (where modellers present final results to authorities), a participatory modelling process (where various stakeholders are involved in various parts of the modelling process), can facilitate the process of formulating locally suggested environmental plans. In this paper this is exemplified by presentation of a case study aiming to produce a locally suggested remedy plan for eutrophication in lakes and costal areas in a catchment in the vicinity of the Swedish HELP basin Motala Ström. In addition, a newly started case study, aiming to produce a locally suggested plan for adaptation to climate changes impact on water resources in a South African HELP basin Thukela is presented.

\section{Methods and case study area}

The Kaggebo Bay project was initiated by farmers in the area that drains into the Kaggebo Bay in the Baltic Sea (Fig. 1). The area covers $430 \mathrm{~km}^{2}$. It is shared by three municipalities (Valdemarsvik, Västervik, Åtvidaberg) and two counties

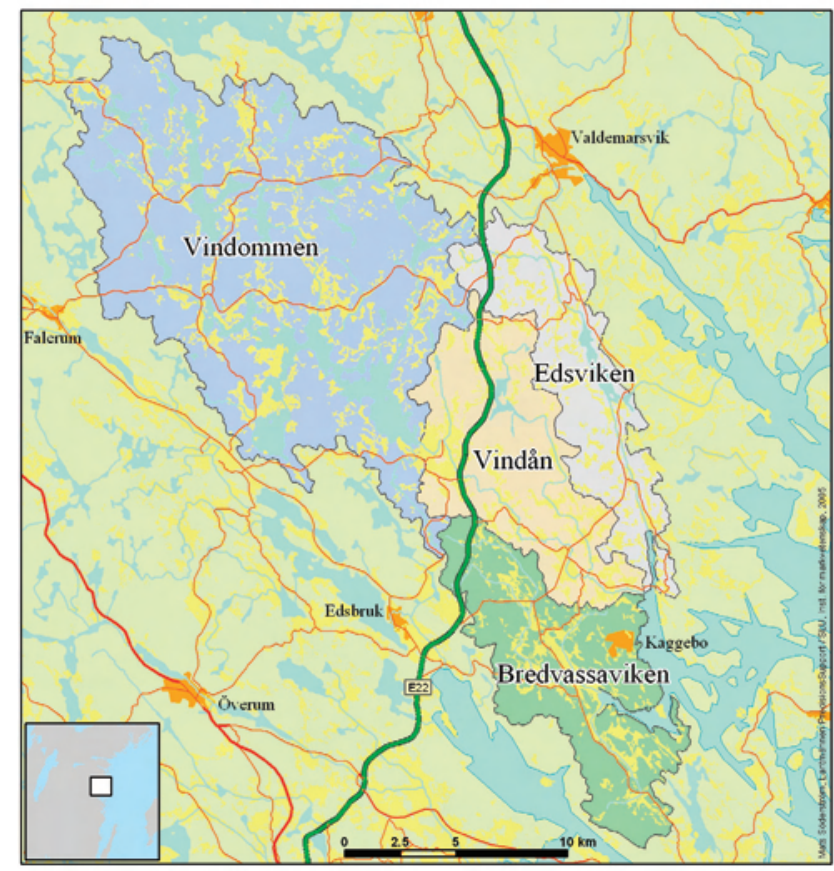

Figure 1

The Kaggebo area, draining into the Baltic Sea, divided in four sub-catchments: Vindommen, Vindån, Edsviken and Bredvassaviken.

(Kalmar, Östergötland). About 18\% of the basin is covered by farm land. There are 2000 inhabitants and approximately 100 farms $>20$ ha. In addition, approximately 350 summer cottages are situated close to the coastline.

The aim of the project was to initiate local and voluntary cooperation linked to the EU Water Framework Directive (WFD) (Council of the European Communities, 2000). The main rationale of the farmers for initiating and participating in the project was that thereby they would be a step ahead of the authorities, which would improve the possibility that they would have a real impact on the local water management. Contacts were established with both modellers and social science researchers, who served as mentors, and later also obtained a research grant for the DEMO-project, aiming to assess how models can be used in stakeholder dialogues. The scope of the project was at this stage limited to eutrophication, with emphasis on reduction of nitrogen and phosphorus loads. When moving from the field level to the catchment level, the stakeholder groups were extended to also include other residents in the drainage area, including a large group of summer cottage owners. There are no large municipal wastewater treatment works in the area, thus all residents have their own responsibility to ensure that their wastewater is treated. In addition, representatives from municipalities, farm advisors, sewage advisors, as well as representatives from the county board that has the comprehensive responsibility for the WFD in the Motala Ström district, were included in the process.

The used 'participatory modelling' approach was based on a number of meetings. Most meetings took place in smaller groups (5 to 20 persons) representing farmers, house-owners (with individual/local sewage treatment) and authorities respectively. Several of these meetings were carried out separately for three sub-catchment groups (Edsviken, Bredvassaviken, Vindommen and Vindån, cf. Fig. 1). Four large meetings were arranged with all stakeholder groups represented. The meetings were facilitated by social-scientists and modellers from the DEMO-project team. 
For some of the meetings other experts on, for example, private sewage systems, or farm advisors, participated. In between the meetings, new knowledge requested by the participants, was produced, based on participatory monitoring, modelling and consultation of experts.

The participatory process did not reach as far as the decision of which models were to be used. This decision was rather based on the availability of models (and modellers) in the DEMO team. For phosphorus transport from agricultural land, the ICECREAM model was used (Larsson et al., 2007), whereas the STANK model (Aronsson and Torstensson, 2004) was used for field leaching of nitrogen. For catchment modelling, the HBVNP model was used (Andersson et al., 2005) linked to the SMHI Coastal Zone model (Marmefelt et al., 2000).

The 'demystification of models' did not aim to ensure that the participants understood all technical details and scientific assumptions used in the model. It included dissemination of information about which processes the model considers, which data are needed, which temporal and spatial scales can be addressed, and the type of results that can be generated, as well as a discussion of uncertainties. A participatory field-campaign monitoring of nutrient status in lakes and rivers was carried out at approximately 30 sites within the catchment on 8 occasions. The sample bottles were then delivered to a ratified laboratory for nutrient analyses (cf. Step 1 in Table 1).

It is the residents in the drainage area that are most directly affected by the environmental status of the lakes and the surrounding coastal zone, as well as of costs and labour related to implementation of remedy plans. Consequently, we hypothesised that locally suggested goals would be more acceptable than goals defined by experts, and such goals were therefore defined by the participants. In order to be meaningful for people in the basin, these goals addressed desirable uses of water bodies, not to theoretical thresholds of, e.g. concentrations (cf. Steps 2 and 3 in Table 1).

During several meetings, both in larger heterogeneous and smaller homogenous groups, discussions were held concerning which remedies that are applicable and feasible in the catchment (cf. Step 4 in Table 1). In discussions, applicability was related to local natural conditions (e.g. soil types, shape of fields), regulations of where and under which conditions subsidies can be obtained, as well as other practical and economical considerations. Feasibility was related to the easiness and cost to implement the remedies. Discussions were also held during the meetings concerning which principles that should be used for the geographical distribution of remedies. Should for example the locally suggested remedy plan recommend that all farmers and possessors of private sewage systems should do the same efforts (equality) or should remedies be located where they can be expected to be the most cost efficient? Shall efficiency of remedies be related to expected impacts in the coastal zone or on the impact on lakes or both? Scenario modelling of the impact of various remedies and combinations of remedies was carried out for actions that were judged by the participants to be of local interest. The impact on nutrient transport and in some cases also the cost was calculated for adapted nitrogen fertilisation, catch crops, increased spread of manure during spring (and less during autumn), redistribution of manure from agricultural land with large pools of phosphorus to soils that are more poor in phosphorus, buffer strips close to water courses, constructed wetlands, improvement of wastewater treatment, and use of phosphate-free detergents (cf. Step 4 in Table 1).

However, it is not enough to know that measures are efficient. In addition assessments were made of obstacles for
TABLE 1

Six steps towards a locally suggested remedy plan for reduced eutrophication

Step 1: How is it today - and why?

Knowledge exchange between modellers and local stakeholders. 'Demystification of models'. How can we ensure that the model results actually represent real conditions? What uncertainties are there? Discussions of results from modelling of 'today's conditions'. Who contributes, how much, and where?

Step 2: How do we want it to be?

Definition of local goals, linked to wanted conditions in lakes and coastal areas.

Step 3: How much do we have to improve?

Definition of the deviation between 'today's conditions' and (i) local goals; (ii) nationally stipulated WFD goals; and (iii) locally adaptations of the Swedish national goal 'No eutrophication'.

Step 4: How can we reach to goals - and what does it cost?

4a: Possible type of actions. Definition of locally feasible measures as well as of their costs.

4b: Possible combinations of actions. Estimate of the maximal impact of individual measures, as well as of impact and costs of various combinations of measures (with consideration to where in the drainage area they are carried out).

Step 5: What obstacles can be defined - and how can they be overcome?

Definition of prerequisites needed to ensure that remedies will be implemented.

Step 6: Remedy plan - what needs to be done 2007-2015?

Definition of a remedy plan for fulfilment of set goals for reduction of nutrient loads in lakes as well as in the local transport of nutrients from land to sea.

implementation of measures. These were based on about 40 interviews with farmers and summer cottage owners in the catchments, as well as reflections from small and large group meetings (c.f. Step 5 in Table 1). During meetings, discussions were also held concerning foreseen developments of the region, as well as climate change, which both are factors that have a potential to change nutrient conditions in the catchment and the coastal zone during the coming 10 to 20 years. No scenarios based on the possible impacts of these factors were, however, modelled.

Finally, outcomes from the previous steps were summarised into a locally suggested remedy plan of (c.f. Step 6 in Table 1).

\section{Results}

\section{Step 1: The current situation - and why?}

This dialogue about the possibilities and limitations of used models did initially decrease the confidence in the models used (and possibly also in the modellers themselves), since so many uncertainties were revealed. However, as especially the farmers experience similar uncertainties in the daily management of their land, after these uncertainties had been discussed more thoroughly, there was agreement that uncertainties are unavoidable. However, the farmers wanted to, compared with the original plan, put more emphasis on combining modelling 
with more monitoring than available from the operational network, which led to the initiation of the performed field campaign monitoring programme of water samples for nutrient analyses of riverine water. By being honest about the limitations of the models, the experts were therefore, at the 'end of the day', perceived to be honest, and the stakeholders' motivation to improve the models' predictability by providing local information, was significantly increased. During this stage it was critical that the modellers were able to demonstrate the potential of the models, i.e. to show why models, in spite of uncertainties, can assist in environmental planning. It was also critical to show that the models proposed had been validated against monitored data and that it was ascertained beyond doubt that they were based on upto-date scientific knowledge.

In order to ensure that all stakeholder groups participated with the same possibility to influence the process, the three groups involved (farmers, house-owners, municipality representatives) were provided with similar information and the possibility of a similar degree of involvement. It was a request, by the farmers, that the initial stage of the project be based on separate meetings for farmers, other residents and for authorities, so that people could speak more freely. This had the advantage that the different stakeholder groups got the possibility to build a level of confidence and common understanding of both their own role and other's roles in the eutrophication process before common meetings were arranged.

In addition to stakeholder validation of 'hard data', such as farm management practices, soil mapping and present methods used for wastewater treatment, discussion with farmers made it possible to collect 'soft data' in the form of local observations of processes (e.g. occurrence of surface runoff, macropores or stream-bank erosion). However, it was not feasible to include this information to a significant extent in the model parameterisation, since neither spatial resolution nor description of flow paths allowed for this.

For nitrogen, the modelled source apportionment showed that farming was the dominating source. For phosphorus, the background value from agricultural land was relatively high, i.e. the transport is high also from post-agricultural land. It was also shown that emissions from the sewage systems of rural households were a significant source. From the perspective of the remedy plan, an important input to the discussion was the fact that measures for reduction of wastewater emissions from rural households had a higher potential to reduce phosphorus loads, than the potential to reduce phosphorus transport by applying measures linked to agricultural practices (Fig. 2). The modelling results did thus show that, although agriculture is the main source of phosphorus leaching, agricultural land will, even after treatment measures have been carried out, contribute significantly to the nutrient loads, whereas emissions from rural households can be reduced almost totally.

\section{Step 2: How do we want it to be?}

When the project was carried out, it was still not finally decided how the goals of the WFD were to be defined. The national Swedish environmental goal 'No eutrophication', stipulates that the anthropogenic load of phosphorus should be reduced by $20 \%$ and nitrogen by $30 \%$ by 2010 , compared to the 1995 levels. These goals are, however, national; which means that regional/ local goals could differ.

Based on the project participants' priority list (Table 2), and a translation of these priorities into levels of nutrient concentrations, 'bubbles' of desirable levels of nutrient concentration
Phosporus Transport to the Sea

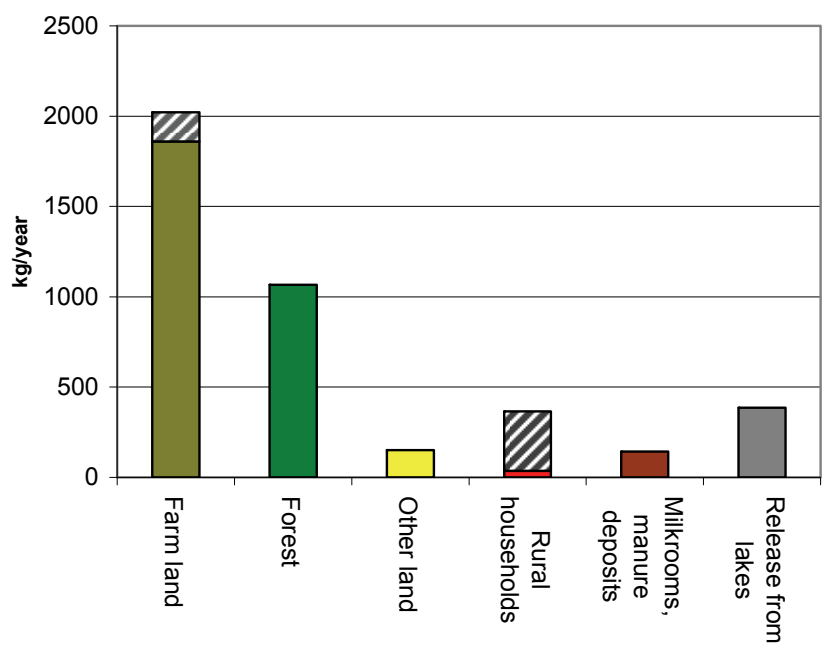

Figure 2

Source apportioned transport of phosphorous to the sea (kg/year). The striped parts of the bars indicate the part that, according to the simulations, can be remediated.

TABLE 2

Prioritised goals for the coastal zone and for lakes

Prioritised goals for Prioritised goals for lakes the coastal zone

\begin{tabular}{|l|l|}
\hline $\begin{array}{l}\text { 1. No unnatural algae } \\
\text { blooms }\end{array}$ & 1. Good fishing \\
\hline 2. Good fishing & 2. No unnatural algae blooms \\
\hline 3. No dead bottoms & 3. Rich bird life \\
\hline 4. Pleasant baths & $\begin{array}{l}\text { 4. Tasty and healthy drinking water } \\
\text { for animals as well as for humans }\end{array}$ \\
\hline 5. Rich bird life & 5. Pleasant baths \\
\hline
\end{tabular}

were constructed. The 'bubbles' relate to optimal concentrations for the local goals 'no unnatural algae blooms', 'drinking water of good quality', and 'rich bird life'. The overlapping area of all bubbles indicates the optimal level of nutrients. A concentration level below the dotted line indicates risk for blue green algae bloom. These local goals were compared to the modelled 'reference level' (i.e. the nutrient concentration that would occur if there were no emissions from wastewater or from agricultural activities in the upstream catchment), as well as to the modelled today's average concentration, and the 'good status' concentrations defined by the suggested national WFD goal. In Fig. 3, local desires (overlap of the bubbles) and national goals (which were available for phosphorus only), are shown for the two largest lakes in the catchment (Vindommen and Rånen). For Lake Rånen (Fig. 3b) it was revealed that it was not possible to reach the local desired outcomes, not even with the most drastic reduction of anthropogenic loads to this lake. (Fig. 3b). This raised discussions about whether remedies should rather be directed towards improving the retention capacity of the lake than towards only reducing the input of nutrients to the lake. In addition, it raised a discussion about whether it made sense to strive towards achieving all goals for all the lakes in the catchment.

\section{Step 3: How much to we have to improve?}

The participants stressed that not only the coastal zone, but also 
A. Vindommen - manages the locally suggested goal, as well as the suggested WFD goal

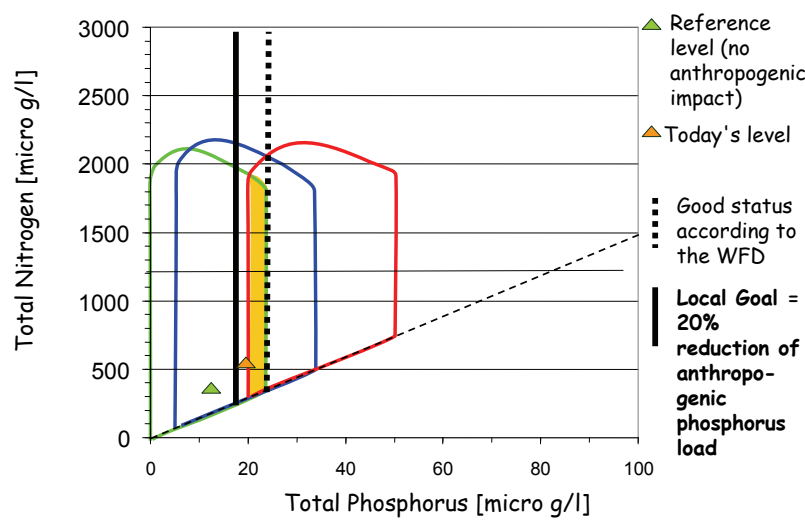

B. Rånen - does not manage locally suggested, neither suggested WFD goals

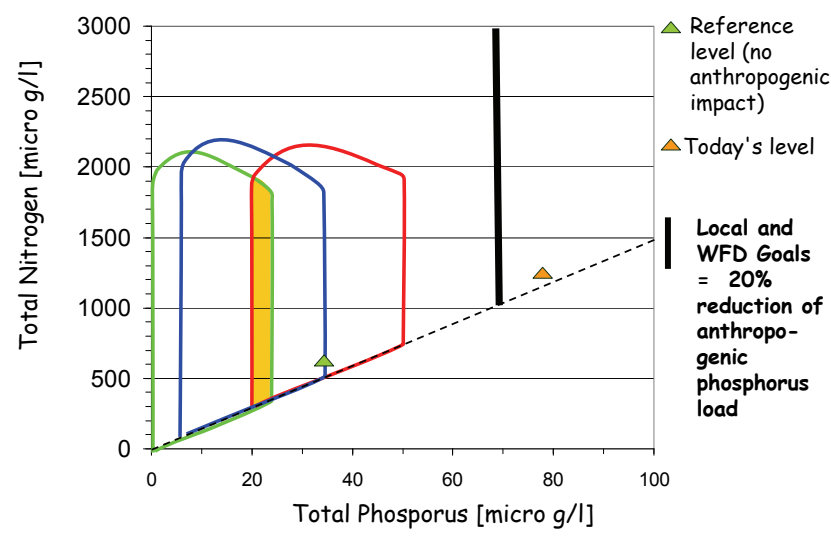

Figure 3

Goals for the two major lakes. Green: "no unnatural algae bloom". Blue: "drinking water of good quality". Reed: "rich bird life". Yellow: overlap of all goals.

the two major lakes in the drainage basin should be in focus. This was especially pointed out by residents in the upstream parts of the basin. In addition to the fact that people were concerned about their nearby water bodies, the fact that the future of the lakes, in contrast to the future of the coastal zone, mainly depends on local actions, was the main reason for this statement.

Lake Vindommen: Despite the fact that local objectives, as well as suggested WFD goals had been fulfilled (Fig. 3a), the participants suggested that, in line with the Swedish National Environmental Goals, the anthropogenic phosphorus load should be reduced by $20 \%$ before 2015 . Their suggestion was based on the fact that part of the phosphorus that is entering the lake will accumulate in the lake and gradually deteriorate its environmental status.

Lake Rånen: The participants doubted that it would be realistic to reach the previously defined locally desired goals (Fig. 3b). Until 2015 they wanted to work toward reaching the WFD goal of 'good status'. Based on model results and their own monitoring programme, the participants stressed that the retention of phosphorus in the lake is very low, which means that remedies linked to farming practices or rural household emissions need to be combined with restoration of the lake.
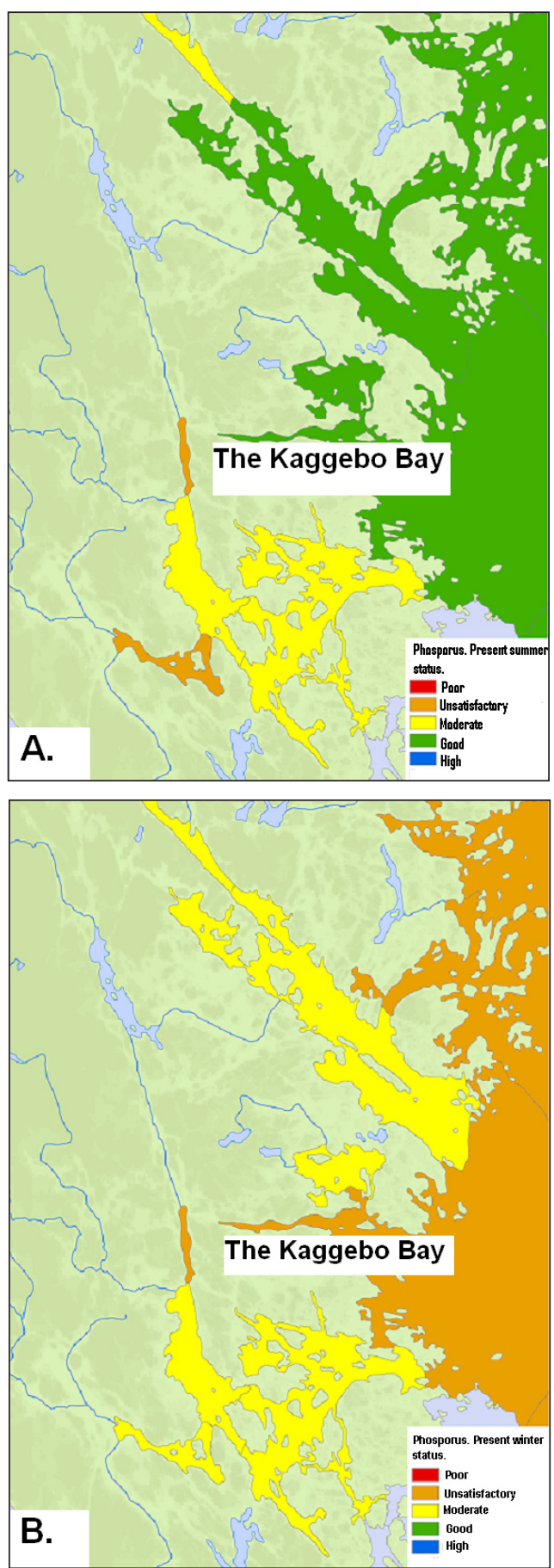

Figure 4

Present status of phosphorus concentrations during A: summer and B: winter, with the suggested WFD classifications.

The coastal zone: The model results showed that the goals were reached for nitrogen, but that phosphorus concentrations were significantly higher than the preliminary WFD goals), as well as the locally desired goals (Fig. 4). Consequently the phosphorus concentrations needed to be reduced by 10 to $25 \%$. These goals cannot be reached by solely implementing remedies within the local drainage area, since only $10 \%$ of the phosphorus in the coastal area emanates from local sources. However, the participants were willing to contribute their share, but with recognition in the remedy plan that fulfilment of environmental goals in the coastal zone needs to be based on actions within the whole 


\section{Nitrogen and phosphorus concentrations in Lake Rånen - impact of remedies}

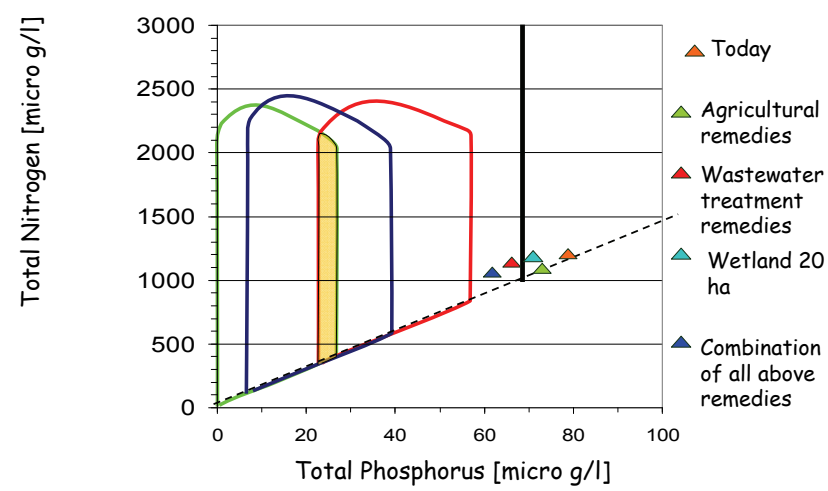

Figure 5

Scenarios of possibilities to reach goals in Lake Rånen with various remedies. (cf. Fig. 3). The black line indicates the WFD goal (maximum two times the reference level).

drainage basin of the Baltic Sea. The locally suggested goal for nutrient emissions from land to the coastal zone was set higher than the national one for phosphorus, and lower than the national goal for nitrogen. This local decision was based on that the result from the modelling suggested this approach as the most efficient way to mitigate eutrophication in the local coastal zone.

\section{Step 4: How can we reach the goals - and what does it cost?}

As stated in Step 3, since it did not seem possible, based on the scenario modelling, to reach the locally desired status of Lake Rånen, it was decided by participants to stick to the WFD goal which allowed for a phosphorus concentration up to two times the 'reference level'. The black line in Fig. 5 shows the WFD goal, with the prerequisite that the reference condition is based on that no phosphorus is retained in this lake. However, there was a fear among the participants that authorities would not allow for use of a modelled 'reference level'. The relatively high 'reference level' at the outlet of the lake, which was verified against the participatory monitoring programme, was mainly due to the fact that the Lake no longer acts as a sink for phosphorus.

For Lake Rånen, model results showed that a high level (90\%) of phosphorus reduction of wastewater was the most costefficient remedy (Fig. 5). It was also shown that nitrogen-reducing remedies in agriculture had to be balanced with phosphorusreducing remedies in order to avoid blue-green algae bloom (Fig. 5). Both these facts were considered in the local remedy plan, in addition to suggestions of restoration of the lake.

For the coastal zone, based on discussions with the participants, the impacts on coastal water from four combinations (scenarios) of remedies in the catchment were modelled (Fig. 6). The scenario 'maximal remedies in the whole catchment' was based on the fact that all remedies seen as acceptable in at least one of the three sub-catchment groups are carried out in all sub-catchments (cf. Fig. 1). The scenario 'locally suggested remedies' only included implementation of remedies in those sub-catchments where they were suggested. The scenario 'geographical optimisation' was based on concentrating remedies to where they were most cost-effective. They only included constructed wetlands and agricultural remedies in areas downstream of Lake Vindommen, as well as a lower level of nutrient reduction of household wastewater $(70 \%$ vs. $90 \%$ for phosphorus, as today vs. $50 \%$ for
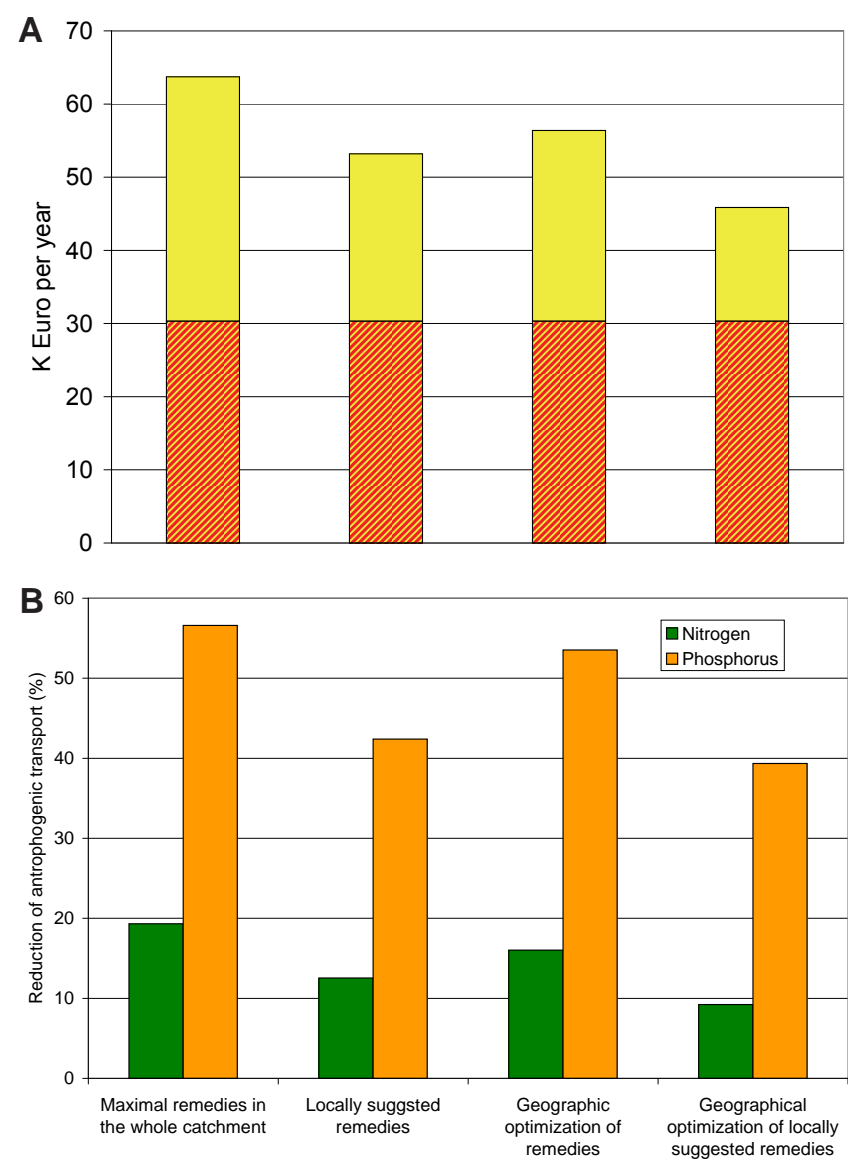

Figure 6

A: Modelled cost (red/yellow = household wastewater treatment, yellow = agricultural measures) and B: Modelled reduction of phosphorous from four scenarios of how to reduce anthropogenic nutrient transport to the Kaggebo Bay.

nitrogen) upstream of Lake Vindommen. Costs for rural household wastewater treatment (shown with red/yellow pattern) are paid by house owners, whereas agricultural treatment measures are paid by subsidies (shown in yellow). The locally suggested goal of $30 \%$ reduction of anthropogenic phosphorus catchment load to the sea was reached with all four scenarios and three of the scenarios reached the $10 \%$ reduction of the nitrogen load (Fig. 6). Consequently, in spite of the fact that only a minor part of the phosphorus in the bay originated from the catchment, the scenario modelling showed that measures in the catchment had the potential to remove approximately a third of the lag between today's level of concentrations and the WFD goal 'good status' for the bay. This fact was emphasised by participants as showing that what they had done in the catchment had an impact, not only on lakes but also on the coastal zone.

\section{Step 5: Which obstacles can be identified - and how can they be overcome?}

Wastewater treatment: Many hesitated to divide the catchment into zones with different demands on wastewater treatment levels since people have to pay for improvements with their own money. If it had to be done, it was emphasised that such a division should be based on sound scientific criteria, not on administrative borders and should preferably be combined with subsidisation or other types of encouragements. It was 
suggested to strive towards 'high level of treatment' for the entire catchment by 2015, but to prioritise in order that the first ones requested to implement the new criteria would be the ones closest to the coast, as well as those that have very unsatisfactory solutions currently. Summer cottages should be prioritised later than houses used all year around. It was emphasised that this strategy needed to be based on cooperation between the three municipalities involved, in order to harmonise inventories, advice to residents and control in the catchment. In addition, the participants wanted to strive towards reuse of wastewater nutrients to local farms. It is often argued that farmers are not willing to use wastewater sludge on their fields. However, participating farmers stressed that it is rather a problem of the willingness of consumers to accept products grown on fields fertilised by wastewater sludge.

Wetlands: In general, there was a positive attitude towards constructed wetlands. During the discussions, it was made clear that the interest to create wetlands increased if they could be combined with grazing and be made attractive for birdlife. In the locally suggested remedy plan a follow-up project was suggested, aiming to find potential locations as well as interested land-owners. This includes finding forms for cooperation between farmers. As an example, it was expressed that if grainfarmers construct wetlands, they could let animal-farmers allow their animals to graze in the wetland areas. Also when it came to wetlands, it was stressed that it was a major obstacle that the levels of subsidies payable for the creation of wetlands differed significantly between the two counties, the border of which runs through the catchment.

Farming remedies: The participating farmers expected that the cooperation between residents, including farmers, municipalities and experts within the project, had increased municipal officers' confidence in that farmers in the region are willing and able to contribute towards improving environmental conditions, without being forced by strict regulations and control from above. The farmers wished that future environmental actions in the catchment could be based on the cooperation initiated in the DEMO-project. In the locally suggested remedy plan it is suggested that decisions, to a greater extent than today, are based on local climatological conditions, landscape characteristics, as well as consideration of citizen's knowledge and desires for the environment of their catchment and surrounding coastal areas. Examples of prevailing regulations that not are based on local conditions included facts like rules for subsidies follow county borders, not the borders of the catchment. Another example concerns the timing for the spreading of manure, where dates today are strictly regulated by the calendar and not the climate. A more dynamic way of estimating when spreading is to be locally allowed was suggested, including short-term as well as long-term weather forecasts, linked to local soil conditions. These regulations should be decided upon in a dialogue between local authorities and farmers, who stressed that they are the ones with experience of when the spreading of manure is feasible and when not. A third example of the importance of considering local conditions when defining the rules for the remedies and make environmental decisions based on cooperation between farmers and authorities concerned buffer zones. With present national regulation, which stipulates a minimum with of $6 \mathrm{~m}$, it was estimated to be difficult to introduce buffer zones in most parts of the catchment due to the fact that many fields have narrow stretches. It was suggested that, based on a dialogue between local authori- ties and farmers, this could be compensated for by enlarging the width of the buffer zones where possible.

Foreseen changes in the coming 10 to 20 years: The participants were aware of the predicted changes in the climate, and are prepared for the fact that this could influence both farming activities, the number of summer cottages and the development of other types of vacation/tourism related activities. This was not only seen as negative for development; some suggested that climate change might lead to increased interest for regional export of agricultural products as well as for tourism in the region. Regarding the development of the agricultural sector, it was emphasised that smaller farms will be aggregated into larger land units. Small fields will be afforested and animal intensity is expected to decrease. Consequently, there will be fewer farmers, but with larger farms. In general, this was emphasised to be positive for the environment, since larger farms in general will have an increased capacity to implement remedies. Although the number of farmers was expected to decrease, it was argued that this not necessary means that the number of inhabitants will decrease, at least in the parts of the catchment. Recently new inhabitants that are either entrepreneurs or that have the possibility to work from home several days per week have moved into the area. In summary, the participants concluded that climate change probably is a factor that hinders the work towards the environmental goals of reduced eutrophication, whereas demographic and agricultural changes most possibly would facilitate the environmental work. For the coastal zone, as mentioned earlier, it was also stressed that the development within the whole drainage basin of the Baltic will determine the future conditions.

\section{Step 6: Remedial plan - what needs to be done 2007 to 2015 ?}

The locally suggested remedial plan of action was delivered to the head of the Water Authority of the Southern Baltic during the final meeting with all stakeholder groups, held in June 2007. The main contents of the plan included:

Initiation of a catchment water board which will be the forum for water resource management, regarding groundwater, surface water and the coastal zone. This board will be a meeting place for residents, authorities and experts, ensuring that this plan will be realised.

Rural wastewater treatment: Fulfilment of a 'high level' of treatment in the entire catchment by 2015, implemented step by step, starting where remediation is most needed. Joint distribution in the catchment (i.e. in all three involved municipalities) of clear and comprehensive information from the three municipalities, including how to meet the forthcoming regulations for phosphate-free detergents. Some type of economic incentive for those who on their own initiative are willing to go ahead of authorities' demands for improvement of wastewater treatment. Initiation of projects that strive towards reuse of nutrients for fertilisation of local agricultural fields.

Farming activities: Mainly focus on phosphorus-reducing remedies. Increased cooperation between farmers and local authorities, ensuring that farmers' knowledge and experiences are considered in implementation of the WFD. Giving advice to farmers on a continual basis and working towards adjustment of regulations so that the local landscape, climate dynamics 
and environmental conditions are considered. Support adaptive management that is continuously updated when new knowledge becomes available. Focus implementation of remedies to areas close to the coast, but also encouragement of phosphor reducing remedies upstream of Lake Vindommen, in order to avoid eventual eutrophication of the lake.

Constructed wetlands: Initiate a new project aimed at finding locations as well as interested land-owners. Provide advice for construction and financing. Work toward harmonisation regulations for subsidies for the construction of wetlands within the catchment.

Restoration of Lake Rånen: Initiate a new project aimed at assessing possibilities for restoration of the lake so that it can start to act as a phosphorus sink. Suggested actions include oxygenation, as well as a increase of the lake level, which might be combined with a mini hydro-power plant to obtain a win-win situation.

\section{Participatory modelling in the Thukela catchment}

Researchers of the Swedish Meteorological and Hydrological Institute (SMHI), Sweden and the Climate Unit of the School of Biosciences and Environmental Engineering at the University of KwaZulu-Natal, and Umgeni Water in Pietermaritzburg, South Africa, have embarked on a collaborative participatory modelling research project. The project's aim is to assess how various stakeholders in water resource management together can develop a locally suggested adaptation plan, focusing on reducing water resource vulnerability to climate variability, as well as climate change. The process is assisted by scenariomodelling, using several climate change scenarios, linked to hydrological/agro-hydrological models, as well as indices of climate vulnerability. During 2007-2009, a set of parallel meetings are arranged for three different stakeholder groups, representing (i) government authorities; research institutes; and companies; (ii) commercial farmers; and (iii) small-scale farmers, followed by a joint meeting with representatives from all three groups, where a locally suggested adaptation plan to climate change impacts on water resources will be compiled. The participants will decide who the plan will be delivered to. Between meetings, the involved Swedish and South African researchers will work together to produce modelling results based on information discussions with the three reference groups. The first set of workshops (August 2007) aimed to define when and whom/ what is too much too little water is a problem, as well as to defined present strategies to deal with water related problems. Based on this information, modelling of climate change impact on water resources was carried out. The second set of workshops (March 2008) aimed to, based on the scenario modelling, identify the main threats, which need to be addressed in adaptation plans. During the third set of workshops (September 2008), challenges, adaptation strategies, including needs and constraints for implementations were discussed. based on this produce a locally suggested adaptation plan will be delivered.

It is hypothesised that experiences gained from this project will partly provide similar experiences as those from the Kaggebo Bay project, whereas other experiences will be significantly different, for example due to the facts that:

- The Kaggebo Bay project deals mainly with remedies whereas the Thukela project is mainly focused on adaptation to climate change
- The residents of Kaggebo Bay are a relatively homogeneous group, compared to the residents of the Thukela basin

- The Kaggebo Bay project was initiated by local residents; the Thukela project by researchers, of which several are foreigners.

\section{Reflection}

Being a researcher, the involvement in a participatory modelling process raises a number of ethical and methodological issues. What are the advantages and disadvantages of giving various weights to expert and stakeholder perspectives? And, can we in our role as participatory modellers be sure that we are really inviting our research objects to an equal communicative relationship where local perspectives, knowledge and priorities is respected to the same extent as central and/or expert perspectives? We believe that to strike a fair balance between expert and stakeholder influence over the process, continuous reflection among ourselves and together with the involved stakeholders is vital. Questions that need to be discussed are whose descriptions of the eco-system and society are considered as legitimate, and whose issues are considered as important and therefore raised during the process? Another reflection is related to the used models capacity to capture information provided from local participants. The used catchment model (HBV-NP) had limitations to consider soft information, e.g. observations of surface runoff or macropore flow into consideration. Increased capability to take advantage of local information is, however usually linked to increased model complexity and data demand. In selection of the 'best model' for participatory modelling, a balance between possibility to include local observations and the data demand of the selected model, compared to data availability has to be made.

\section{Conclusion}

During three years of work within the Kaggebo Bay project, we have concluded that the forms for dialogues between various local water management stakeholders and experts have been very important for the progress of the process to develop a locally suggested remedy plan. The used participatory modelling process has both facilitated and utilised the engagement provided by the participants. It has facilitated exchange of experiences and views between various groups of participants. The process has also increased the understanding of that everybody in the catchment (i.e. not only the farmers) has to contribute towards reducing eutrophication in the catchment and the surrounding costal area. Altogether, a common view of causes, goals and solutions of the eutrophication problem has been obtained. This has a good potential to provide a platform for coming work based on mutual learning and local participation in water resource management in the area. The advantage of implementing such a process is that it can use the local potential to take action to an environmental problem in a way that not easily can be obtained in a 'top down' implementation of different remedies and legal frameworks such as the WFD. The disadvantage is that it is time demanding, and depends on local willingness to participate. In the Kaggebo Bay project this was facilitated by a local 'fire-soul'. It is possible that the positive output would not be obtained in another catchment where a participatory process is initiated from, e.g. authorities or researchers, and where no local 'fire soul' motivates others to participate. This will in a later stage be evaluated by comparing the experiences from the Kaggebo Bay and the Thukela participatory modelling project. 


\section{References}

ALKAN OLSSON J and ANDERSSON L (2007) Possibilities and problems with the use of models as a communication tool in water resource management. Water Resour. Manage. 21 (1) 97-110.

ANDERSSON L, ROSBERG J, PERS BC, OLSSON J and ARHEIMER B (2005) Estimating catchment nutrient flow with the HBV-NP model: Sensitivity to input data. Ambio 34 (7) 521-532.

ARONSSON H and TORSTENSSON G (2004) Beskrivning av ett pedagogiskt verktyg för beräkning av kväveutlakning från enskilda fält och gårdar. Ekohydrologi 78, Swedish University of Agricultural Sciences, Division of Water Quality Management. In Swedish with English abstract.

COUNCIL OF THE EUROPEAN COMMUNITIES (2000) Directive 2000/60/EG of the European Parliament and of the Council of 23 October 2000 establishing a framework for Community action in the field of water policy. Off. J. Eur. Commun. 22.12.2000, L327/1.

DUVAIL S and HAMERLYNCK O (2003) Mitigation of negative ecological and socio-economic impacts of the Diama dam on the Senegal River Delta wetland (Mauritania), using a model based decision support system. Hydrol. Earth Syst. Sci. 7 (1) 133-146.

EAKIN H, MAGENA V, SMITH J, MORENO JL, MARTINEZ JM and Landavazo O (2007) A stakeholder driven process to reduce vulnerability to climate change in Hermosillo, Sonora, Mexico. Mitigation Adapt. Strat. Global Change. 12 (5) 935-955.

GADDIS EJB, VLADICH H and VOINOV A (2007) Participatory modelling and the dilemma of diffuse nitrogen management in a residential watershed. Environ. Model. Software. 22 (5) 619-629.

HORLITZ T (2007) The role of model interfaces for participation in water management. Water Resour. Manage. 21 (7) 1091-1102.
JONSSON A and ALKAN OLSSON J (2005) Participatory modelling - (how) can computer generated information affect the 'room of action' of local stakeholders? Kulturstudier i Sverige, June 13-15, 2005, Norrköping, Sweden.

LARSSON MH, PERSSON K, ULÉN B, LINDSJÖ A and JARVIS NJ (2007) A dual porosity model to quantify phosphorus losses from macroporous soils. Ecol. Model. 205 123-134.

LAUBER TB and KNUT BA (2000) Citizen participation in Natural Resource Management: A Synthesis of HDRU Research. HDRU Series No 00-7. Department of Natural Resources, Human Dimensions Research Unit, Cornell University.

MARMEFELT E, HÅKANSSON B, ERICHSEN AC and HANSEN IS (2000) Development of an Ecological Model System for the Kattegat and the Southern Baltic. SMHI Report Oceanografi No 29, Norrkoping, Sweden.

PAHL-WOSTL C (2002) Participative and Stakeholder-Based Policy Design, Evaluation and Modelling Processes. Integrated Assess. 3 (1) 3-14.

PAHL-WOSTL C (2007) The implications of complexity for integrated resources management. Environ. Model. Software 22 (5) 561-569.

SCHULZE RE (2001) Managing water as a resource in Africa: Are we asking the right questions? Chapter 2 in: Gash JHC, Odada EO, Oyebande L and Schulze RE (2001) Freshwater Resources in Africa. BAHC International Project Office, PIK, Potsdam, Germany. 9-14.

SHERWILL T, ARENDSE L, ROGERS K, SIHLOPHE N, VAN WILGEN B, VAN WYK E and ZEKA S (2007) Stakeholder connectedness and participatory water resource management in South Africa. Water SA 33 (4) 505-512 http://www.wrc.org.za/downloads/ watersa/2007/Jul\%2007/1947.pdf 